\title{
Bilgisayar Değiştirme Kararları için Bir Karar Destek Sisteminin Geliştirilmesi Araştırma Makalesi/Research Article
}

\author{
Muhammet YORULMAZ*, (D) Yusuf Tansel İÇ, (D) Akif SEYREK \\ Endüstri Mühendisliği, Başkent Üniversitesi, Ankara, Türkiye \\ muhammed@baskent.edu.tr, yustanic@ baskent.edu.tr, akifseyrek@gmail.com \\ (Geliş/Received:09.01.2019; Kabul/Accepted:22.05.2019) \\ DOI: $10.17671 /$ gazibtd.510657
}

\begin{abstract}
Özet-Günümüzde bilgisayarlar, kurumlarda ve evlerde yoğun olarak kullanılmaktadır. Ekonomik ömürlerin sonunda bilgisayarlar yenileriyle değiştirilmelidir. Kurumlardaki bilgisayar değiştirme sürecinde, donanım bileșenleri ile ilgili ayrıntılı değerlendirmeler yapılmalıdır. Donanım bileşenleri, işleme kapasitelerine göre sıralanmalı ve değiştirme kararı için yönetim bilgi sistemi raporu olarak yöneticilere sunulmalıdır. Bu çalışmada, bilgisayar sistemlerinin donanım özelliklerini izlemek ve sıralamak için bir karar destek sistemi (KDS) geliştirilmiştir. Geliştirilen KDS'de, çok ölçütlü bir karar verme modeli olarak İdeal Çözüm ile Benzerliklerine Göre Tercihlerin Siralanma Tekniği (TOPSIS) yöntemi kullanılmıştır. Geliştirilen KDS sayesinde, yöneticilerin bireysel kullanıcılar için bilgisayar sistemlerini izlemesi ve derecelendirmesi kolaylaştııılmıştır. Geliştirilen KDS, Türkiye'de Ankara ilinde 125 çalışanı olan bir mühendislik fakültesinde bilgisayarları sıralamak için uygulanmıştır.
\end{abstract}

\section{Development of a Decision Support System for Computer Replacement Decisions}

\begin{abstract}
Nowadays, computers are extensively used in institutions and homes. At the end of the economic life cycles, computers should be replaced with new ones. In the computer replacement process at organizations, detailed evaluations about the hardware components should be carried on. Hardware components must be sorted according to their processing capacities and they should be presented to the managers as a management information system's report to make a replacement decision. In this study, a decision support system (DSS) has been developed to monitor of the hardware specifications of the computer systems. In the developed DSS, Technique for Order Preference by Similarity to Ideal Solution (TOPSIS) method is used as a multi-criteria decision making model. Thanks to the developed DSS, it is facilitated for managers to ranking of the computer systems for individual users. The developed DSS is applied to rank the computers for 125 employees in a faculty of engineering located in Ankara, Turkey.
\end{abstract}

Keywords - hardware components, decision support system, replacement decision, multi-criteria decision making, TOPSIS

\section{GİRIŞ (INTRODUCTION)}

Günümüzde, kurumsal ve bireysel çalışmalarda bilgisayarlar yoğun olarak kullanılmaktadır. Ülkelerin ekonomik durumu ve gelir seviyeleri gibi farklılıklara göre değişmekle beraber bilgisayarlar belirli bir süre sonra faydalı kullanım ömürlerini tamamlamaktadırlar. Örneğin
Amerika, California eyaleti özelinde yapılan bir çalışmada kullanılan bilgisayar sistemlerinin en az 3 en çokta 7 yıl gibi bir kullanım ömrü öngörülmüştür [1]. Masaüstü bilgisayarlar için tahmini ortalama kullanım ömrü 5,9 yılken, dizüstü / notebook bilgisayarlarda ise 5,5 yıldır [2]. Bilgisayarlar, bu süreler sonunda yenileri ile değiştirilmektedir. Kişisel olarak kendi bilgisayarını 
değiştirme kararı bireysel verilebilirken, bir kurumdaki çalışanın kullandığı bilgisayar sisteminin değiştirilmesi yöneticilerin kararına bağlıdır. Hangi bilgisayar sistemlerinin öncelikli olarak değiştirilmesi gerektiği kararını verebilmek için bilgisayarların donanım bileşenleri ayrıntılı takip edilmelidir. Çalışanların kurumlarında kullandıkları bilgisayarlar genellikle kurum demirbaşı olarak kayıtlıdırlar. Demirbaşlar, uzun süre bir yerde kullanılan, kullanıldığı sürece tükenmeyip özelliklerini muhafaza eden, zimmete alınan mallardır. Demirbaş konusu, bilgisayar sistemi olduğunda yüzeysel saklandığında genellikle yalnızca marka, model ve satın alma tarihleri demirbaş kayıtlarında saklanmaktadır. Ayrıntılı olarak da bilgisayarların donanım bileşenleri (CPU, RAM, Disk vs.) de ayrıca saklanabilmektedir.

Demirbaş yazılımında, bilgisayarın donanım bileşenleri hakkında ayrıntılı kayıtlar tutulsa bile, bilgisayarların birbirleri arasında kıyaslamaya dayalı sıralamayı bir ölçüte göre yapabilmek mümkün olmakla beraber sonuçlar yanıltıcı olabilmektedir. Gerçekte, bilgisayarların kendi aralarında sıralamasında göz önünde tutulması gereken birden fazla ölçüt bulunmaktadır. Bilgisayarların performansları ve işlem kapasiteleri ayrı ayrı donanım bileşenlerine bağlıdır. Bir bilgisayar, alınma tarihi yeni bile olsa performans ve işlem kapasitesi açısından satın alma zamanı eski tarihli bir bilgisayardan daha düşük düzeyde olabilir. Genellikle yöneticiler teknisyenlerin ya da bilgisayarı kullanan çalışanın bilgisayar performansı ve işlem kapasitesi hakkında verdikleri öznel bilgiye göre kararlarını vermektedirler. Bu tür kararların nesnel olarak verilmesi ve çalışanlar arasındaki kaynak adaletini bozmaması gerekir. Yöneticinin kararlarının nesnel olarak verilebilmesi için bilgisayar donanım bileşenlerinin ayrıntılı takibi ve donanım bileşenlerinin işlem kapasiteleri-performansları gibi birden fazla farklı ölçüt göz önünde tutularak sıralanabilmeleri gerekmektedir. $\mathrm{Bu}$ sıralama sonuçları yöneticiler için özet ve sade biçimde olmalidir.

Bu çalışmada, bir üniversitenin mühendislik fakültesindeki çalışanların sahip oldukları bilgisayar sistemlerinin donanım özelliklerini takip etmek ve kendi aralarında puanlamak için geliştirilmiş bir Karar Destek Sistemi (KDS) tanıtılmıştır. Geliştirilen KDS sayesinde yöneticilerin çalışanların sahip oldukları bilgisayar sistemlerini izlemesi ve kendi aralarında sıralaması kolaylaştırılmıştır. Sıralama işleminde Çok Ölçütlü Karar Verme (ÇÖKV) tekniği olarak TOPSIS (Technique for Order Preference by Similarity to Ideal Solution) yöntemi kullanılmıştır. Bilgisayar sistemlerinin kendi aralarında puanlanarak sıralanması sayesinde öncelikli ihtiyaçlar saptanabilecek ve satın alma istekleri tespit edilen ihtiyaçlara göre yapılabilecektir. Aynı zamanda geliştirilen sistem sayesinde yöneticilerin, kuruma alınan yeni bilgisayar sistemlerini dağıtırken hangi çalışana öncelikli atama yapılacağına nesnel olarak karar vermelerini kolaylaştırmıştır. Yöneticiler, çalışanların özel çalışma alanlarına göre istenildiği anda ölçüt ağırlık puanlarını değiştirerek farklı senaryolara göre siralamalar yapabileceklerdir. Böylece bilişim kaynakları daha adaletli paylaştırılabilecektir.

$\mathrm{Bu}$ çalıșmanın ikinci bölümünde ÇÖKV yöntemlerine dayanılarak alanyazındaki bilgisayar puanlama-seçim çalışmaları özetlenmiştir. Çalışmanın üçüncü bölümünde tasarlanan KDS ve KDS içinde karar verme yöntemi olarak kullanılan TOPSIS yöntemi hakkında bilgi verilmiştir. Son bölümde ise çalışmanın sonuçları hakkında bilgi verilmiştir.

\section{ALANYAZIN (LITERATURE)}

Alanyazın incelendiğinde, bilgisayar sistemlerinin seçilmesi ve sıralanması problemine dayalı ÇÖKV çalışmalarının bilgisayarların yaygınlaşmaya başladığı yıllara kadar uzandığı görülmektedir. İlk çalışmalardan birisi Borthick ve Schiner (1988) tarafından yapılan çalıșmadır. Küçük işyerlerine satın alınacak sunucu bilgisayar seçimi için AHP (Analytic Hiyerarchy Process) yönteminden yararlanılmıştır [3]. Doyle ve Green (1994) tarafından Veri Zarflama Analizi (VZA) ile bilgisayarları niteliklerine göre karşılaştıran bir çalıșma sunulmuştur. $\mathrm{Bu}$ çalışmada, bilgisayar donanım bileşenlerinin özellikleri VZA girdisi olarak kullanılmıştır [4]. Zviran (1993) tarafından yapılan, belli bir bilgisayar seçimi yerine kurum için bilgisayar ailesi seçimi ve değerlendirmesini amaçlayan çalışmada AHP tekniği kullanılmıştır [5]. Araştırmacı daha sonra bu çalışmayı bir karar destek sistemine dönüştürmüştür [6]. Düzakın ve Demirtaş ise donanım bileşenlerini ayrı ayrı seçerek etkin bir donanım sistemine sahip kişisel bilgisayar sistemi için alternatif öneri oluşturmaya çalışmışlardır. Bilgisayar performans ve işlem kapasitesi için dört temel donanım bileşeni (CPU, RAM, Sabit disk ve ekran kartı) VZA yöntemi ile analiz edilmiştir [7]. Lin ve Liao, dört farklı kullanıcı türüne göre dizüstü bilgisayarların seçiminde VZA yöntemini kullanmış ve fiyat ve performans ölçütleri üzerinden (ağırlık, pil ömrü, sabit disk, ekran boyutu, garanti vs.) analiz yapmışlardır [8]. Erpolat ve Cinemre, dizüstü bilgisayarın performansının değerlendirildiği VZA ve AHP içeren karma bir yöntem önermişlerdir [9]. Pekkaya ve Aktogan ise dizüstü bilgisayarlar seçimi için değişik ÇÖKV yöntemleri ile karşılaştırmalı senaryolar kullanarak sıralamaları değerlendirmişlerdir. Karar ölçütleri hız, marka, kapasite, görüntü, fiyat ve çevre birimleri olarak belirlenmiştir [10]. Lakshmi ve arkadaşları diz üstü bilgisayar seçimi için TOPSIS yönteminden yararlanmışlardır. Donanım bileşenleri özellikleri yanında garanti, büyüklük, batarya ömrü gibi ölçütleri de değerlendirmede kullanmışlardır [11]. Adalı ve Işık, yine dizüstü bilgisayar seçimi için çok amaçlı optimizasyon yöntemlerinden yararlanmışlardır. Kriter ağırlıkları AHP ile belirlendikten sonra dizüstü bilgisayar alternatifleri MULTIMOORA (full multiplicavite form multi-objective optimization by ratio analysis) ve MOOSRA (multiobjective optimization on the basis of simple ratio analysis) yöntemleri ile sıralanmıştır [12].

$\mathrm{Bu}$ çalışmada ise alanyazındaki çalışmalardan farklı olarak, bilgisayarların performanslarına göre 
sıralanmasının yanı sıra, çalışanlara en uygun bilgisayarın atanması ve/veya ekonomik ömrünü dolduran bilgisayarların yenileriyle değiştirilesi kararlarında kullanılabilecek nitelikte bir KDS geliştirilmiştir. Geliştirilen KDS bu özelliği ile alanyazına katkı yapan özgün bir çalışmayı sunmaktadır. KDS'nin geliştirilme ve uygulanma adımları ilerleyen bölümlerde sunulmaktadır.

\section{MATERYAL ve METOT (MATERIALS and METHOD)}

\subsection{Verilerin Toplanmasl (Data Collection)}

KDS’yi geliştirmeye başlamadan önce, ilk olarak çalışanların bilgisayar donanım özelliklerini tespit etmek gerekmektedir. Demirbaş yazılımlarındaki bilgisayar marka, model ve alınma tarihi gibi genel bilgiler ve varsa donanım özellikleri öğrenilebilir. Donanım özellikleri ile ilgili bilgilerin olmadığı varsayılırsa, bilgisayarların donanım bileşenlerinin özelliklerini tespit etmek için çeşitli yazılımlar mevcuttur. $\mathrm{Bu}$ tür bilgilendirme yazılımlarının bilgisayarlara kurulması ve çalıştırılması gerekmektedir. Çalışanların güvenlik ve gizlilik hassasiyetlerinden dolayı bu yönteme başvurulmamıştır. $\mathrm{Bu}$ yöntem yerine Windows işletim sistemine sahip bilgisayarların özelliklerini daha kolay bir şekilde görüntülenebilmesi için başka pratik yöntemler araștırılmıştır. En kolay yöntem olan bilgisayarın donanım özelliklerinin incelenmesi yönteminde ise sinırlı sayıda özellik bilgisi edinilmiştir. Daha ayrıntılı veri elde etmek için DirectX işlevselliğini test etmek ve video veya sesle ilgili donanım sorunlarını gidermek için kullanılan bir tanı arac1 olan "dxdiag" (DirectX Diagnostic Tool) ve "msinfo" komutları kullanılmıştır. Komut isteminden ya da çalıştır emri olarak "msinfo" ve "dxdiag" komutu verildiğinde bilgi ekranları gelmektedir. Her iki yöntemle de bilgisayarın donanım özellikleri pratik bir şekilde tespit edilebilmektedir. Alanyazın incelendiğinde bilgisayar seçiminde alternatifleri sıralamak için kullanılan ölçüt kümeleri birbirlerinden farklı olsa da, ortak ölçüt kümesinin aşağıdaki bileşen özellikleri olduğu görülmüştür. Kurum çalışanlarının bilişim kaynaklarının araştırılması yapılarak aşağıdaki verileri toplanmıştır. Bu veriler; İşlemci hızı $(\mathrm{GHz})$, İşlemci modeli (çekirdek say1s1) (adet), RAM (GB), Sabit disk kapasitesi (GB) olarak belirlenmiştir.

\subsection{TOPSIS Yöntemi (TOPSIS Method)}

ÇÖKV yöntemleri, seçilecek alternatifleri kendi aralarında sıralamaya yararlar. Günümüzde üç boyutlu yazıcı seçiminden, firma seçimine kadar çok geniş bir yelpazedeki seçme ve sıralama problemlerine çözüm için kullanılmaktadır [13, 14]. TOPSIS yöntemi, Hwang ve Yoon tarafından 1980 yılında geliştirilmiş olan ve alanyazında en yaygın kullanım alanına sahip olan ÇÖKV yöntemlerinden biridir [14]. TOPSIS'in seçilme nedeni kolay programlanabilir olması ve diğer yöntemlerle de karma olarak kullanılabilmesidir [15]. Alternatiflerin en iyiden en kötüye doğru sıralanmaları ana prensibine dayanır. TOPSIS yönteminin uygulanmasında, çalışanlar tarafindan kullanılan bilgisayarlar $\left(\mathrm{PC}_{1}, \mathrm{PC}_{2}, \ldots, \mathrm{PC}_{\mathrm{n}}\right)$ "alternatifler", donanım bileşenleri özellikleri $\left(\mathrm{C}_{1}, . ., \mathrm{C}_{4}\right)$ ise "ölçütler" olarak ele alınmıştır. Belirlenen ölçütler yukarıdaki belirtildiği gibi işlemci hızı $\left(\mathrm{C}_{1}\right)(\mathrm{Ghz})$, işlemci çekirdek sayısı $\left(\mathrm{C}_{2}\right)$ (adet), RAM bellek kapasitesi $\left(\mathrm{C}_{3}\right)$ (GB) ve sabit disk kapasitesi $\left(\mathrm{C}_{4}\right)$ (GB) olarak belirlenmiştir. TOPSIS'in 6 adımı ve toplanan veriler üzerinde uygulanması aşağıda açıklanmıştır.

\section{Adım 1: Karar matrisinin oluşturulması}

Karar matrisinin satırlarında performansları sıralanmak istenen bilgisayarlar, sütunlarında ise karar vermede kullanılacak donanım bileşenleri özellikleri yer alır. Donanım bileşenleri özellikleri karar verici tarafından oluşturulan başlangıç karar matrisi olan " $A$ ” Eş. 1'deki gibi gösterilir. Eş. 1'deki karar matrisinde $i=1, \ldots, m$ alternatif sayısını, $j=1, \ldots, 4$ değerlendirme ölçütü sayısını gösterir.

$$
A_{i j}=\left[\begin{array}{cccc}
a_{11} & a_{12} & \ldots & a_{1 n} \\
a_{21} & a_{22} & \ldots & a_{2 n} \\
\cdot & & & \cdot \\
\cdot & & & \cdot \\
\cdot & & & \cdot \\
a_{m 1} & a_{m 2} & \ldots & a_{m n}
\end{array}\right]_{i=1, \ldots, m ; j=1, \ldots, 4}
$$

Kullanılan bilgisayarlar için oluşturulan karar matrisi Tablo 1'deki gibidir.

Tablo 1. Karar matrisi (Decision matrix)

\begin{tabular}{lllll}
\hline & $\mathbf{C}_{\mathbf{1}}$ & $\mathbf{C}_{\mathbf{2}}$ & $\mathbf{C}_{\mathbf{3}}$ & $\mathbf{C}_{\mathbf{4}}$ \\
\cline { 2 - 5 } $\mathrm{PC}_{1}$ & 3.4 & 7 & 8 & 500 \\
$\mathrm{PC}_{2}$ & 2.7 & 2 & 2 & 1000 \\
$\mathrm{PC}_{3}$ & 3.3 & 3 & 4 & 500 \\
$:$ & $:$ & $:$ & $:$ & $:$ \\
$\mathrm{PC}_{\mathrm{n}}$ & 3.3 & 3 & 4 & 500 \\
\hline
\end{tabular}

Adım 2: Normalize karar matrisinin oluşturulması

A matrisinin her bir sütununda bulunan elemanları, bulundukları sütundaki elemanların değerlerinin kareleri toplamının kareköküne bölünerek (Eş. 2) normalize değerlerinden oluşan normalize karar matrisi $(R)$ belirlenir (Eş. 3).

$$
r_{i j}=\frac{a_{i j}}{\sqrt{\sum_{i=1}^{n} y_{i j}^{2}}} \quad i=1, \ldots, m ; j=1, \ldots .4
$$




$$
R_{i j}=\left[\begin{array}{cccc}
r_{11} & r_{12} & \ldots & r_{1 n} \\
r_{21} & r_{22} & \ldots & r_{2 n} \\
\cdot & & & \cdot \\
\cdot & & & \cdot \\
\cdot & & & \cdot \\
r_{m 1} & r_{m 2} & \ldots & r_{m n}
\end{array}\right]
$$$$
j=1, \ldots, 4
$$

$$
i=1, \ldots, m \text {; }
$$

Kullanılan bilgisayarlar için oluşturulan $\mathrm{R}$ matrisi Tablo 2'deki gibidir.

Tablo 2. Normalize karar matrisi (Normalized decision matrix)

\begin{tabular}{lcccc}
\hline & $\mathbf{C}_{\mathbf{1}}$ & $\mathbf{C}_{\mathbf{2}}$ & $\mathbf{C}_{\mathbf{3}}$ & $\mathbf{C}_{\mathbf{4}}$ \\
\cline { 2 - 5 } $\mathrm{PC}_{1}$ & 0.623 & 0.889 & 0.872 & 0.408 \\
$\mathrm{PC}_{2}$ & 0.495 & 0.254 & 0.218 & 0.816 \\
$\mathrm{PC}_{3}$ & 0.605 & 0.381 & 0.436 & 0.408 \\
$:$ & $:$ & $:$ & $:$ & $:$ \\
$\mathrm{PC}_{\mathrm{n}}$ & 0.605 & 0.381 & 0.436 & 0.408 \\
\hline
\end{tabular}

\section{Adım 3: Ağırllklı standart karar matrisinin oluşturulması}

Belirlenen ölçütlere 10-puan ölçeği ile (1 en kötü puan, 10 en iyi puan olmak üzere) verilen önceliklerin toplamlarına göre ağırlık değerleri belirlenir. 1 ile 10 arasında öncelik dereceleri normalize edilerek ölçüt ağırlıkları $\left(w_{i}\right)$ Tablo 3'deki gibi elde edilir.

Tablo 3. Ölçütlerin önemi ve ağırlıkları (Criteria preference and weights)

\begin{tabular}{lrc}
\hline Ölçütler & Önem & Ăğırlık (wi) \\
\hline $\mathrm{C}_{1}$ & 10 & 0,40 \\
$\mathrm{C}_{2}$ & 5 & 0,20 \\
$\mathrm{C}_{3}$ & 7 & 0.28 \\
$\mathrm{C}_{4}$ & 3 & 0,12 \\
\hline Toplam & 25 & 1,00 \\
\hline
\end{tabular}

Burada önemli olan husus tüm ölçütler için belirlenecek olan ağırlıkların toplamının, Eş. 4'deki gibi 1'e eşit olmasidır.

$$
\sum_{i=1}^{n} w_{i}=1
$$

Daha sonra $R$ matrisinin $j$. sütununda yer alan normalize ölçüt değerleri, ölçütün ağırlık puanı ile çarpılarak $V$ matrisi Eş. 5'deki gibi elde edilir.
$V_{i j}=\left[\begin{array}{cccc}w_{1} r_{11} & w_{2} r_{12} & \ldots & w_{n} r_{1 n} \\ w_{1} r_{21} & w_{2} r_{22} & \ldots & w_{n} r_{2 n} \\ \cdot & & & \cdot \\ \cdot & & & \cdot \\ \cdot & & & \cdot \\ w_{1} r_{m 1} & w_{2} r_{m 2} & \ldots & w_{n} r_{m n}\end{array}\right]$

$j=1, \ldots, n$

Kullanılan bilgisayarlar için oluşturulan V matrisi Tablo 4'deki gibidir.

Tablo 4. V matrisi (V- matrix)

\begin{tabular}{lcccc}
\hline Bilgisayar & $\mathbf{C}_{\mathbf{1}}$ & $\mathbf{C}_{\mathbf{2}}$ & $\mathbf{C}_{\mathbf{3}}$ & $\mathbf{C}_{\mathbf{4}}$ \\
\hline $\mathrm{PC}_{1}$ & 0,249384 & 0,1778 & 0,244404 & 0,04899 \\
$\mathrm{PC}_{2}$ & 0,198040 & 0,0508 & 0,061101 & 0,09798 \\
$\mathrm{PC}_{3}$ & 0,242049 & 0,0762 & 0,122202 & 0,04899 \\
$:$ & $:$ & $:$ & $:$ & $:$ \\
$\mathrm{PC}_{\mathrm{n}}$ & 0,242049 & 0,0762 & 0,122202 & 0,04899 \\
\hline
\end{tabular}

Adım 4: Pozitif ideal $\left(A^{*}\right)$ ve negatif ideal $\left(A^{-}\right)$çözümlerin oluşturulması

Pozitif ideal çözüm setinin oluşturulabilmesi için $V$ matrisindeki ağırlıklandırılmış değerlendirme ölçütlerinin en büyük değerleri (değerlendirme enküçükleme üzerine ise küçük değerler) Eş. 6'daki formülle bulunur.

$$
A^{*}=\left\{\left(\max _{i} v_{i j} \mid j \in J\right),\left(\min _{i} v_{i j} \mid j \in J^{\prime}\right\}\right.
$$

Eş. 6'dan hesaplanacak pozitif ideal çözüm seti $A^{*}=\left\{v_{l}{ }^{*}\right.$, $\left.v_{2}{ }^{*}, \ldots, v_{n}{ }^{*}\right\}$ şeklinde gösterilebilir. Negatif ideal çözüm seti ise, $V$ matrisindeki ağırlıklandırılmış değerlendirme ölçütlerinin en küçükleri (değerlendirme enbüyükleme üzerine ise en büyükler) seçilerek oluşturulur. Negatif ideal çözüm setinin bulunması aşağıdaki Eş. 7'de gösterilmiştir.

$$
A^{-}=\left\{\left(\min _{i} v_{i j} \mid j \in J\right),\left(\max _{i} v_{i j} \mid j \in J^{\prime}\right\}\right.
$$

Eş. 7'den hesaplanacak set $A^{-}=\left\{v_{1}^{-}, v_{2}^{-}, \ldots, v_{n}^{-}\right\}$şeklinde gösterilebilir. Gerek pozitif ideal, gerekse negatif ideal çözüm seti, değerlendirme ölçütü sayısı kadar elemandan oluşmaktadır. Elde edilen setler Eş 8 ve Eş 9'daki gibidir

$A^{*}=\{0,177 ; 0,249 ; 0,244 ; 0,097\}$

$A^{-}=\{0,051 ; 0,198 ; 0,061 ; 0,048\}$ 
Adım 5: Ideal ve ideal olmayan çözümlere uzaklıkların hesaplanmast

Faktör değerinin pozitif ideal ve negatif ideal çözüm setinden uzaklıklarının bulunabilmesi için "Öklid Uzaklık Yaklaşımı'ndan yararlanılmaktadır. Uzaklık değerleri ise ideal ayırım $S_{i}^{*}$ (Eş. 10) ve negatif ideale uzaklık ölçüsü $S_{i}^{-}$(Eş. 11) olarak adlandırılmaktadır.

$$
\begin{aligned}
& S_{i}^{*}=\sqrt{\sum_{j=1}^{n}\left(v_{i j}-v_{j}^{*}\right)^{2}} \\
& S_{i}^{-}=\sqrt{\sum_{j=1}^{n}\left(v_{i j}-v_{j}^{-}\right)^{2}}
\end{aligned}
$$

Adım 6: ideal çözüme göreli yakınlığın hesaplanması

Her bir karar noktasının ideal çözüme göreli yakınlığının $C_{i}^{*}$ hesaplanmasinda ideal ve negatif ideal ayırım ölçülerinden Eş 12'deki gibi yararlanılır.

$$
C_{i}^{*}=\frac{S_{i}^{-}}{S_{i}^{-}+S_{i}^{*}}
$$

Kullanılan bilgisayarlar için bulunan Ayırım $S_{i}^{*}, S_{i}^{-}$ve $C_{i}^{*}$ değerleri Tablo 5'deki gibidir.

Tablo 5. Siralama sonuçları

\begin{tabular}{lccc}
\multicolumn{4}{c}{ (Ranking results) } \\
\hline Bilgisayar & $\boldsymbol{S}_{\boldsymbol{i}}^{-}$ & $\boldsymbol{S}_{\boldsymbol{i}}^{*}$ & $\boldsymbol{C}_{\boldsymbol{i}}^{*}$ \\
\hline $\mathrm{PC}_{1}$ & 0,2288 & 0,0489 & 0,8239 \\
$\mathrm{PC}_{2}$ & 0,0489 & 0,2288 & 0,1763 \\
$\mathrm{PC}_{3}$ & 0,0794 & 0,1664 & 0,3230 \\
$:$ & $:$ & $:$ & $:$ \\
$\mathrm{PC}_{\mathrm{n}}$ & 0,0794 & 0,1664 & 0,3230 \\
\hline
\end{tabular}

Eş. 12'de $C_{i}^{*}$ değeri $[0,1]$ aralığında bir değer alır ve $C_{i}^{*}=$ 1 ilgili karar noktasının ideal çözüme mutlak yakınlığını gösterir.

\subsection{KDS'nin Geliştirilmesi (Development of the DSS)}

KDS'nin hızlı bir şekilde geliştirilebilmesi için MS Access yazılımı kullanılmıştır. KDS'lerin ortaya çıkışı tarihsel olarak 1950 ve 1960'lı yıllara kadar uzanmaktadır [16]. KDS karmaşık karar verme ve problem çözmeyi desteklemek için kullanılacak bilgisayara dayalı çözümler olarak tanımlanabilir. Klasik bir KDS, bilgiye erişim için kullanılacak bir veritabanı, model tabanı ve kullanıcıya rapor ve grafikler sunan güçlü bir arayüzden oluşur. Esas ortaya çıkış amacı karar vericilere yardımcı olmaktır [17]. Karar vericilere yararlı bilgiler sunarak analiz sürecinde destek olması beklenir [18]. Geliştirilen KDS'nin yöneticiler için gerekli olan aşağıdaki kararların verilmesinde destek sağlaması istenmiştir.

- Mevcut bilgisayarların donanım özellikleri nelerdir?

- Mevcut bilgisayarların işlem kapasitesi ve performans olarak kendi aralarında sıralama puanı nedir?

- Bu sıralama puanına sahip bilgisayarlar hangi çalışanlar tarafindan kullanılmaktadır?

Toplanan verilerin saklanabilmesi ve bilgiye erişim için geliştirilen veritabanının varlık ilişki diyagramı (entity relationship diagram- ER) Şekil-1 deki gibidir.

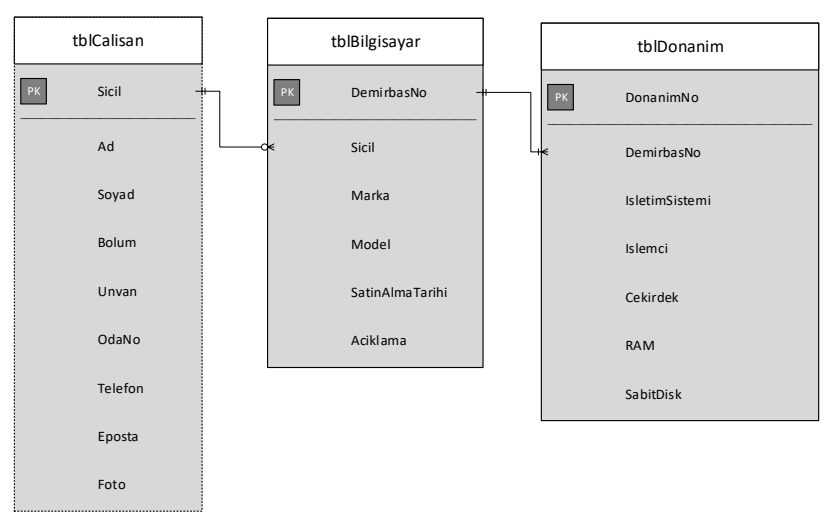

Şekil 1. Varlık ilişki diyagramı (Entity relationship diagram)

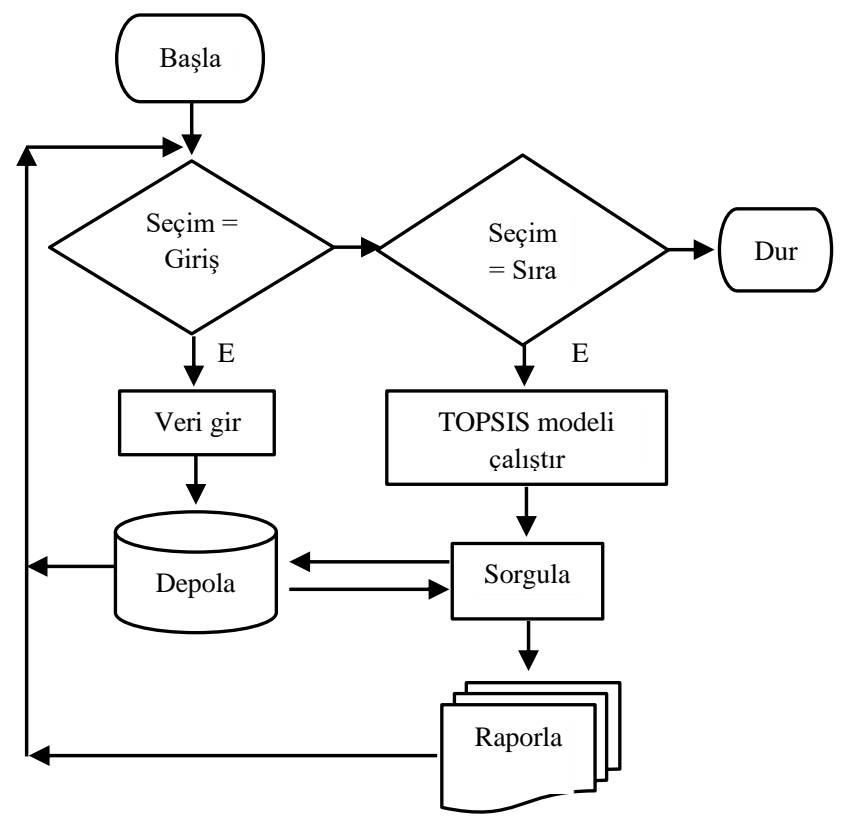

Şekil 2. Akış diyagramı (Flow chart)

KDS'lerin model tabanında, depolanan veriyi analiz etmek için çok çeşitli modeller kullanılır. Kullanıcıların bu modelleri doğrudan kullanabilmeleri gerekir [19]. 
Geliştirilen KDS'de karar verme modeli olarak TOPSIS kullanılmıştır. Bölüm 3.2 'de anlatılan TOPSIS adımları SQL (Structured Query Language) sorgu cümleleri yardımıyla elde edilmiştir. Böylece sisteme yeni bir bilgisayar eklendiğinde puanlar ve dolayısıyla sıralamalar yeni duruma göre değişmektedir. KDS'nin algoritmasının mantıksal akış diyagramı Şekil 2'deki gibidir.

Geliştirilen KDS'de kolay veri girişi yapmak ve sonuçları yöneticilere özet ve sade halde sunmak için arayüz formları oluşturulmuştur. Arayüzde oluşturulan ana menü ekranı; bilgi giriş, sorgular ve rapor olmak üzere 3 ana bölüme ayrılmıştır. Ana menü ekranındaki bilgi giriş kısmında olan çalışan listeleri görüntülenmektedir. $\mathrm{Bu}$ bölümde çalışanlara ait "Sicil, Ad, Soyad, Bölüm” gibi özlük bilgileri bulunmaktadır. Ayrıca bu bölümden yeni kayıt Şekil 3'deki gibi eklenebilmektedir.

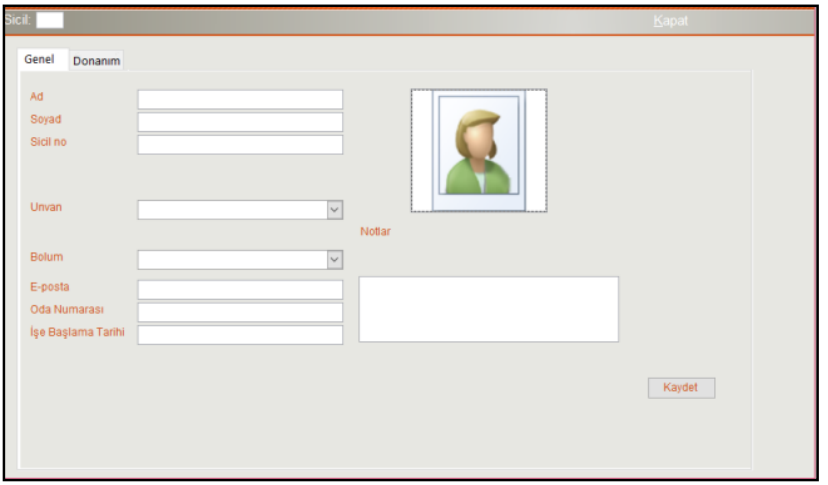

Şekil 3. Çalışan kayıt ekranı (Worker registration screen)

Şekil 3 kayıt ekranında bulunan donanım sekmesinden çalışanın bilgisayarının donanım bileşeni özellikleri Şekil 4'deki gibi girilmektedir.

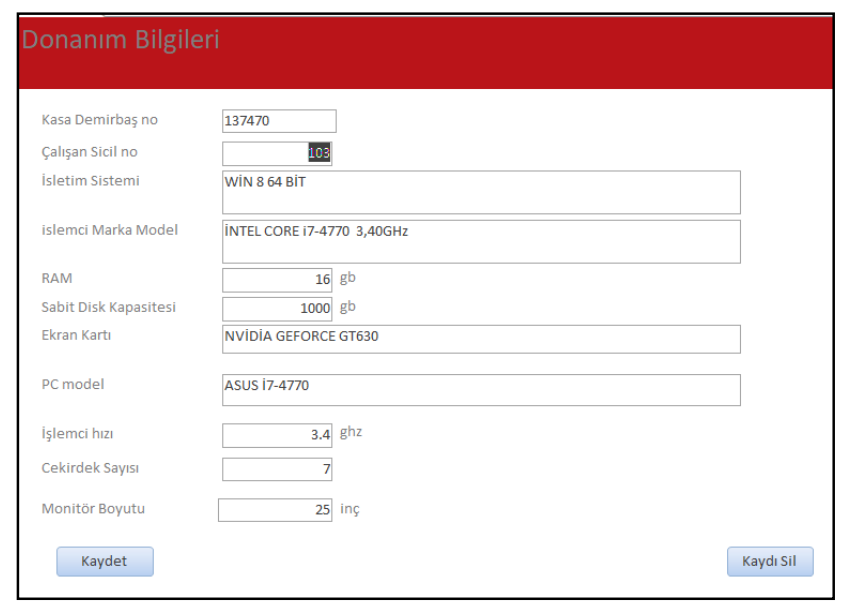

Şekil 4. Donanım bileşenleri giriş ekranı (Hardware components input screen)

Ana menü ekranındaki Bilgi Girişi kısmındaki "ölçüt ağırlıkları" bölümünde ise, bilișim kaynaklarının puanlamasında kullanılan ölçüt puan değerleri Şekil 5'deki gibi değiştirilebilmektedir. Bu ağırlıklar değiştirildiğinde sıralamalar değişen ağırlıklara göre yeniden yapılmaktadır.

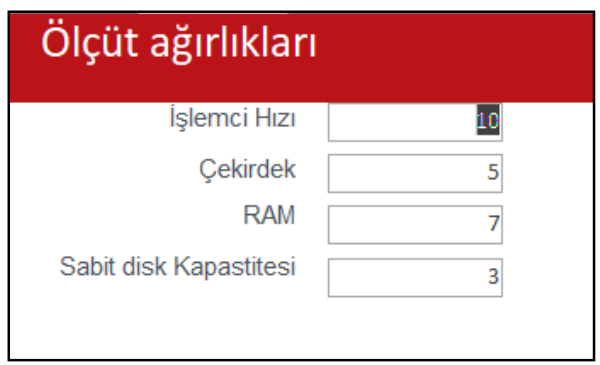

Şekil 5. Kriter ağırlıkları ekranı (Criteria weights screen)

Ana menü ekranındaki "Sorgular" kısmında çalışanların bilgisayar puanları hesaplanmaktadır. En yüksek puandan en düşük puana doğru olacak şekilde puan sıralamaları Şekil 6'da verilmiştir. Yönetici, puana göre azalan ya da artan sırada olacak şekilde istediği sıralama biçimini seçebilmektedir. Şekil 6'da gerçek çalışanların isimleri bulanıklaştırılmıştır.

\section{BULGULAR (FINDINGS)}

Şekil 6'da elde edilen rapor, Tablo 3'de verilen ölçüt puanlarına göre yapılan sıralama sonucuna göre elde edilmiştir. Tablo 3'de verilen ölçüt ağırlıklarına göre puanlama çalışmanın bilgisayarlardaki işlemci hız ve çekirdek sayısını önceleyen $\left(\mathrm{C}_{1}=10, \mathrm{C}_{2}=5, \mathrm{C}_{3}=7, \mathrm{C}_{4}=3\right)$ orijinal senaryodur (Senaryo-0). Orijinal senaryonun yanında ağırlık puanlarının değiştirildiği iki ek senaryo daha kurgulanmıştır.

$\mathrm{Bu}$ senaryolardan ilki (Senaryo-1) RAM ve sabit disk büyüklüğünü yani bellek kapasitesini daha önemli $\left(\mathrm{C}_{1}=7\right.$, $\mathrm{C}_{2}=3, \mathrm{C}_{3}=10, \mathrm{C}_{4}=5$ ) olarak kurgulayan senaryodur. Özellikle sinyal işleme (görüntü, video gibi) araştırmalarında diğer alanlara göre nispeten daha fazla bellek kapasitelerine ihtiyaç duyulmaktadır. Bu alanda çalışanların bilgisayarlarının durumunu izlemek için kurgulanmıştır. İkinci senaryoda (Senaryo-2) ise tüm ağırlık puanları eşit $\left(\mathrm{C}_{1}=5, \mathrm{C}_{2}=5, \mathrm{C}_{3}=5, \mathrm{C}_{4}=5\right)$ verilerek bir sıralama yapılmıştır. Böylece toplam üç senaryoya göre karar vericilere değişik senaryolara göre özet raporlar sunulmuştur. Senaryolar ve bu senaryolara göre bilgisayarların değişen sıralamaları Tablo 6'da verilmiştir.

Tablo 6. Senaryolara göre bilgisayar sıralamaları (Computer rankings according to scenarios)

\begin{tabular}{|c|c|c|c|c|c|c|c|}
\cline { 2 - 7 } \multicolumn{1}{c|}{} & \multicolumn{6}{c|}{ Siralamalar } \\
\cline { 2 - 8 } \multicolumn{1}{c|}{} & $\mathbf{1 .}$ & $\mathbf{2 .}$ & $\mathbf{3 .}$ & $\mathbf{4 .}$ & $\mathbf{5 .}$ &. & $\mathbf{1 2 5}$. \\
\hline $\begin{array}{c}\text { Senaryo } \\
\mathbf{0}\end{array}$ & $\mathrm{PC}_{15}$ & $\mathrm{PC}_{9}$ & $\mathrm{PC}_{55}$ & $\mathrm{PC}_{5}$ & $\mathrm{PC}_{43}$ &. & $\mathrm{PC}_{21}$ \\
\hline $\begin{array}{c}\text { Senaryo } \\
\mathbf{1}\end{array}$ & $\mathrm{PC}_{1}$ & $\mathrm{PC}_{13}$ & $\mathrm{PC}_{14}$ & $\mathrm{PC}_{15}$ & $\mathrm{PC}_{7}$ &. & $\mathrm{PC}_{106}$ \\
\hline $\begin{array}{c}\text { Senaryo } \\
\mathbf{2}\end{array}$ & $\mathrm{PC}_{15}$ & $\mathrm{PC}_{9}$ & $\mathrm{PC}_{5}$ & $\mathrm{PC}_{55}$ & $\mathrm{PC}_{43}$ &. & $\mathrm{PC}_{47}$ \\
\hline
\end{tabular}




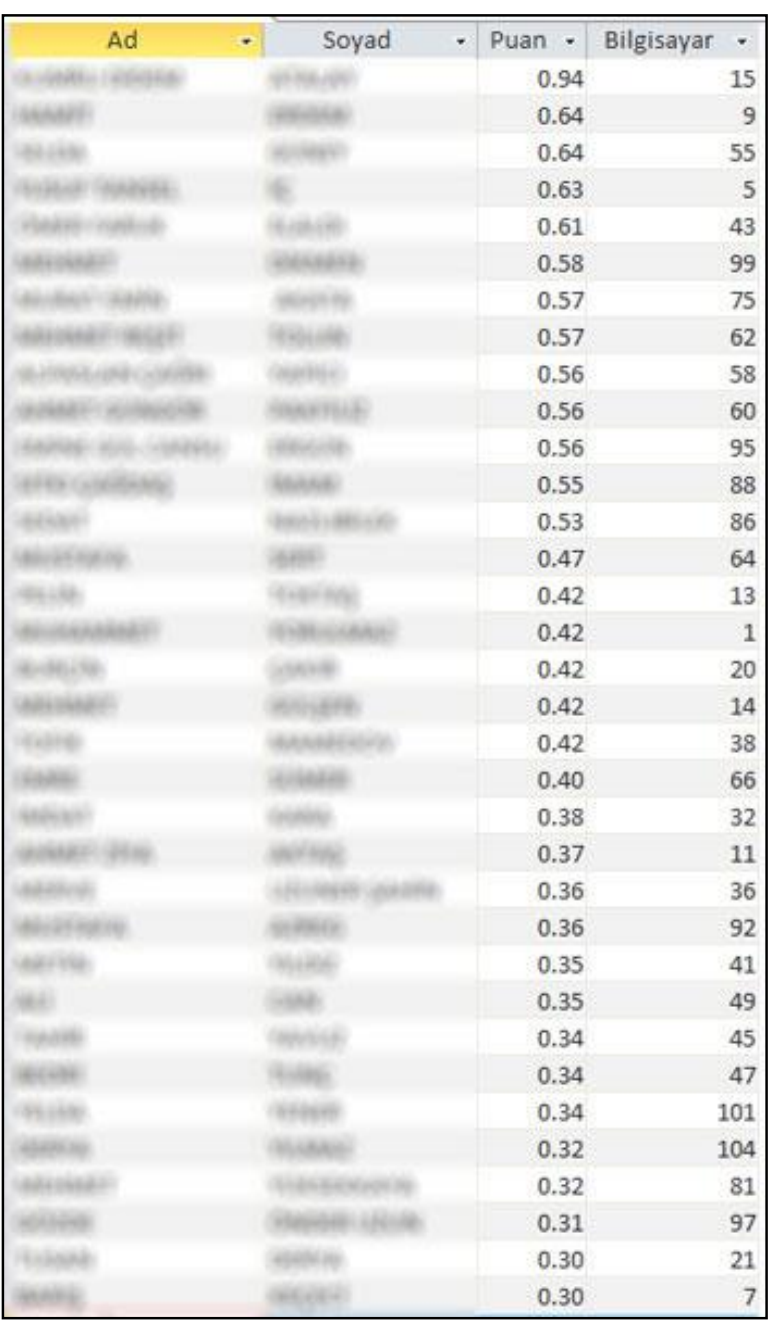

Şekil 6. Bilgisayar sıralamaları (Computer rankings)

Senaryolar arasındaki siralamaların tutarlılığını hesaplamak için senaryoların sıralama değerleri üzerinde Spearman Sıra İlişki (Spearman's Rank-Order Correlation) testi yapılmıştır. Senaryoların sıralama sonuçlarından hesaplanan Spearman sıra işlişki katsayıları ve z değerleri Tablo 7'de özet olarak verilmiş ve Sonuçlar bölümünde ayrıca yorumlanmıştır.

Tablo 7. Spearman sıra ilişki sonuçları (Spearman Rank-Order Correlation Results)

\begin{tabular}{llll}
\hline Sonuçlar & S0-S1 & S0-S2 & S1-S2 \\
\hline $\mathrm{r}_{\mathrm{S}}$ & 0,974 & 0.975 & 0.966 \\
$\mathrm{z}$ & 5,677 & 5.684 & 5.632 \\
\hline
\end{tabular}

S0: Senaryo 0, S1:Senaryo1, S2:Senaryo2

$\mathrm{r}_{\mathrm{s}}$ : Spearman'ın sıra ilişki katsayısı

\section{SONUCLAR (CONCLUSIONS)}

Geliştirilen KDS, bir üniversitenin mühendislik fakültesi ölçeğinde uygulanmıştır. Fakülte bünyesinde çalışan 125 çalışan ve kullandıkları bilgisayarların donanım bileşenlerinin özellikleri veri olarak KDS'nin veritabanına kaydedilmiştir. Bu sayede, yöneticilerin çalışanların sahip oldukları bilgisayar sistemlerini izlemesi ve kendi aralarında sıralaması kolaylaştırılmıştır. Veritabanına yeni bir çalışan ya da yeni bir bilgisayar eklendiğinde sıralamalar yeniden oluşturulacaktır. Bilgisayar sistemlerinin kendi aralarında sıralanması sayesinde öncelikli ihtiyaçlar saptanabilecek ve satın alma istekleri tespit edilen ihtiyaçlara göre yapılabilecektir.

Yöneticiler, istedikleri anda ölçütlerin farklı ağırlık senaryolarına göre yeniden sıralama yapabileceklerdir. Çalışmada önerilen orjinal senaryo (Senaryo 0) bilgisayarın hızlı işlem yapabilme kapasitelerine göre sıralanmasını sağlamaktadır. Bilgisayar hızı için mikro işlemci hızı ölçüt ağırlığı diğer ölçütlerden daha büyük verilmiştir. Böylece çalışanların bilgisayarlarının hız kıyaslaması kolaylıkla yapılabilmektedir. Daha çok RAM bellek ihtiyacının öne çıktığı çalışma alanları için ise Senaryo 1 ile gösterilmiştir. Bu senaryoda en büyük ağırlık RAM kapasitesi ölçütü olarak belirlenmiştir. Sabit disk kapasitesi de mikroişlemci çekirdek sayısından daha büyük ağırlığa sahiptir. Özellikle resim, video ve sinyal işleme alanlarında çalışan araştırmacılar çok büyük ölçekli veri dosyaları üzerinde çalışmaktadırlar. $\mathrm{Bu}$ tür dosyaları yedeklemek için sabit disk kapasitelerinin büyük olması istenir. Büyük boyutlu dosyalar üzerinde işlem yapabilmek için de bilgisayarın RAM kapasitesi diğer ölçütlerden daha önemlidir. Örneğin, gece boyu uyku sırasında kaydedilmiş bir hastaya ait 8 saatlik horlama sesleri yaklaşık 2.3 GB lık bellek gereksinimi oluşturmaktadır. Aynı hastanın video görüntülerini de kaydetmek gerektiğinde ise çözünürlük ve kare sayısı kalitesine bağlı olarak çok daha büyük bellek alanlarına ihtiyaç duyulmaktadır. Kaynakların daha adaletli paylaştırılması adına çalışanların özel çalışma alanları mutlaka dikkate alınmalıdır. Senaryolar sayesinde ihtiyaçlara göre bilgisayarların göreli durumu izlenebilecektir. İzlemeler sonucunda duruma göre çalışanlar arasında da bilgisayar değişiklikleri yapılabilir.

Eğer yönetici, çalışanlar arasındaki farklılıkları dikkate almak istemiyor çalışanların aynı tür alanlarda çalıştığını düşünüyorsa, tüm ölçütleri eşit olarak da verebilir. Bu durum çalışmada, Senaryo 2 ile gösterilmiştir. Tablo 6'da tüm senaryolara göre bilgisayar sıralamaları verilmiştir. Örneğin, orijinal senaryoya göre hız açısından diğerlerine göre daha yüksek puan alan $\mathrm{PC}_{15}$ birinci sırada yer alırken, Senaryo 1'e göre birinci siradaki bilgisayar $\mathrm{PC}_{1}$ ve Senaryo 2 için yine $\mathrm{PC}_{15}$ 'tir. Önerilen sistemle, yönetici ölçüt ağırlıklarını değiştirerek yeni senaryolar oluşturabilir. Böylece yeni senaryolara göre yeni sıralamalar yapabilir. Örnek senaryolara göre sıralamalarda değişiklikler olması beklenen bir durumdur. Senaryo siralamalarının birbirleri ile tutarlılığını gösteren, Tablo 7'de özetlenmiş Spearman sıra ilişki sonuçlarına göre $\% 95$ güven düzeyinde $(\alpha=0,05$, z>1,647) senaryoların birbirleri ile tutarlı olduğu söylenebilir.

İleriki çalışmalarda KDS üzerine benzer ÇÖKV teknikleri senaryo olarak eklenerek birbirleri ile karşılaştırmalar yapilabilir. 


\section{KAYNAKLAR (REFERENCES)}

[1] H. Y. Kang, J. M. Schoenung, "End-of-life personal computer systems in California: Analysis of emissions and infrastructure needed to recycle in the future", J. Hazard. Mater., 321-325, 2006.

[2] A. Kumar, M. Holuszko, D. C. R. Espinosa, "E-waste: An overview on generation, collection, legislation and recycling practices", Resour. Conserv. Recycl., 122, 32-42, 2017.

[3] A. F. Borthick, J. H. Scheiner, "Selection of Small Business Computer Systems: Structuring a Multi-Criteria Approach", Journal of Information Systems, 3(1), 10, 1988.

[4] J. Doyle, R. Green, "Strategic choice and data envelopment analysis: Comparing computers across many attributes", J. Inf. Technol., 9(1), 61-69, 1994.

[5] M. Zviran, "A comprehensive methodology for computer family selection”, J. Syst. Softw., 22(1), 17-26, 1993.

[6] M. Zviran, "Select: A decision support system for computer family selection", J. Comput. Inf. Syst., 39(2), 101-112, 1998.

[7] E. Düzakın, S. Demirtaş, "En Uygun Performansa Sahip Kişisel Bilgisayarların Oluşturulmasında Veri Zarflama Analizinin Kullanımı", Ç.Ü. Sos. Bilim. Enstitüsü Derg., 14(2), 265-280, 2005.

[8] C. H. Lin, D. Y. Liao, “A data envelopment analysis approach for performance evaluation of IT products", Conf. Proc. - IEEE Int Conf. Syst. Man Cybern., 5, 3772-3777, 2007.

[9] S. Erpolat, N. Cinemre, "Notebook Seçiminde Hibrit Bir Yaklaşım: Analitik Hiyerarşi Yöntemine Dayalı Veri Zarflama Analizi", Istanbul Univ. J. Sch. Bus. Adm., 40(2), 207-225, 2011.

[10] M. Pekkaya, "Dizüstü Bilgisayar Seçimi: DEA, TOPSIS ve VIKOR ile Karşılaştırmalı Bir Analiz”, Int. J. Econ. Soc. Res., 10(1), 107-126, 2014.
[11] M. Lakshmi, T., V. P. Venkatesan, M. Aruldoss, "Identification of a Better Laptop with Conflicting Criteria Using TOPSIS", Int. J. Inf. Eng. Electron. Bus., 7(6), 28-36, 2015.

[12] E. Aytaç Adalı, A. Tuş Işık, "The multi-objective decision making methods based on MULTIMOORA and MOOSRA for the laptop selection problem", J. Ind. Eng. Int., 13(2), 229-237, 2017.

[13] C. Çetinkaya, M. Kabak, E. Özceylan, "3D Printer Selection by Using Fuzzy Analytic Hierarchy Process and PROMETHEE”, Bilişim Teknol. Derg., 10(4), 371-380, 2017.

[14] M. Yurdakul, Y. T. İç, "Türk Otomotiv Firmalarinin Performans Ölçümü ve AnalizineYönelik TOPSIS Yöntemini Kullanan Bir Örnek Çalışma”, J. Fac. Eng. Arch. Gazi Univ., 18(1), 1-18, 2003.

[15] Y. T. İç, H. Duran, B. Keçecİ, E. İlik, B. Bilgiç, “Çok Yanıtlı Taguchi Eniyilemesine Yönelik Bir Bilgisayar Uygulamasının Geliştirilmesi Development of a Computer Application for MultiResponse Taguchi Optimization”, Politek. Derg., 19(3), 311-323, 2016.

[16] V. Arslan, G. Yilmaz, "Karar Destek Amaçlı Bir Raporlama Aracı", Bilişim Teknol. Derg., 3(1), 11-16, 2010.

[17] J. P. Shim, M. Warkentin, J. F. Courtney, D. J. Power, "ScienceDirect.com - Decision Support Systems - Past, present, and future of decision support technology", Decis. Support, 33, 111-126, 2002.

[18] E. Aydemir, “Akademik Personel Performans Değerlendirmesinde Bir Karar Destek Sistemi Önerisi”, Bilişim Teknol. Derg., 12, (2), 131-140, 2019

[19] K. C. Laudon, J. P. Laudon, Management information systems, 12th ed., Pearson, 2012. 